\title{
Myc Enforces Overexpression of EZH2 in Early Prostatic Neoplasia via Transcriptional and Post-transcriptional Mechanisms
}

\author{
Cheryl M. Koh ${ }^{1}$, Tsuyoshi Iwata ${ }^{1}$, Qizhi Zheng ${ }^{1}$, Carlise Bethel ${ }^{1}$, Srinivasan \\ Yegnasubramanian'2,3,4,5, Angelo M. De Marzo 1,2,3,4,5 \\ Departments of Pathology ${ }^{1}$, Urology ${ }^{2}$, Oncology ${ }^{3}$, The Sidney Kimmel Comprehensive Cancer Center at Johns Hopkins ${ }^{4}$ and \\ The Brady Urological Research Institute ${ }^{5}$, The Johns Hopkins University, School of Medicine, Baltimore, MD, USA \\ Correspondence to: Angelo M De Marzo, email: ademarz@jhmi.edu
}

Keywords: Myc, EZH2, prostate cancer

Received: September 13,2011, Accepted: September 19, 2011, Published: September 19, 2011

Copyright: @ Koh et al. This is an open-access article distributed under the terms of the Creative Commons Attribution License, which permits unrestricted use, distribution, and reproduction in any medium, provided the original author and source are credited.

ABSTRACT:

EZH2 is part of the PRC2 polycomb repressive complex that is overexpressed in multiple cancer types and has been implicated in prostate cancer initiation and progression. Here, we identify EZH2 as a target of the MYC oncogene in prostate cancer and show that MYC coordinately regulates EZH2 through transcriptional and post-transcriptional means. Although prior studies in prostate cancer have revealed a number of possible mechanisms of EZH2 upregulation, these changes cannot account for the overexpression EZH2 in many primary prostate cancers, nor in most cases of high grade PIN. We report that upregulation of Myc in the mouse prostate results in overexpression of EZH2 mRNA and protein which coincides with reductions in miR-26a and miR-26b, known regulators of EZH2 in some non-prostate cell types, albeit not in others. Further, in human prostate cancer cells, Myc negatively regulates miR-26a and miR-26b via direct binding to their parental Pol II gene promoters, and forced overexpression of $\mathrm{miR-26a}$ and $\mathrm{miR}-26 \mathrm{~b}$ in prostate cancer cells results in decreased EZH2 levels and suppressed proliferation. In human clinical samples, miR-26a and miR-26b are downregulated in most primary prostate cancers. As a separate mechanism of EZH2 mRNA upregulation, we find that Myc binds directly to and activates the transcription of the EZH2 promoter. These results link two major pathways in prostate cancer by providing two additional and complementary Mycregulated mechanisms by which EZH2 upregulation occurs and is enforced during prostatic carcinogenesis. Further, the results implicate EZH2-driven mechanisms by which Myc may stimulate prostate tumor initiation and disease progression.

\section{INTRODUCTION}

EZH2 is a histone lysine methyltransferase that is part of the PRC2 polycomb repressive complex. It catalyzes the tri-methylation of histone 3 on lysine 27 (H3K27me3), which is involved in chromatin remodeling and the silencing of genes, including homeobox genes involved in differentiation [1-4]. EZH2 is overexpressed during prostate cancer progression $[5,6]$ and promotes proliferation, invasion, tumor formation, and metastasis of prostate cancer cells, and is considered to be involved in the progression to advanced disease [7-11]. Prior studies indicated that at least three separate mechanisms could result in EZH2 upregulation in prostate cancer.
Saramäki et al. found that a region on chromosome 7q36.1 harboring EZH2 is amplified in approximately $20 \%$ of castrate resistant prostate cancers [8]. More recently, Varambally et al. used a bioinformatics approach to nominate miR-101 as a potential microRNA that can target EZH2 mRNA for silencing [5]. miR-101 was shown to specifically target EZH2 for down regulation in prostate cancer cells, and the miR-101 locus was deleted in $37.5 \%$ of localized prostate cancers and $66.7 \%$ of castrate-resistant metastatic prostate cancer cases. Additionally, Yu et al. and Kunderfranco et al. reported that the ETS gene family members ERG and ESE3 could activate and repress EZH2 transcription, respectively $[12,13]$. Interestingly, the original study by Varambally 
et al. documented upregulation of EZH2 in the majority of all prostate cancer cases, as well as in the majority of all high grade PIN, a key prostate cancer precursor lesion [6]. The findings published to date, therefore, can explain EZH2 upregulation in only a subset of cases of primary and metastatic prostate cancer, and the mechanisms by which EZH2 is upregulated in PIN lesions and in a subset of early carcinomas have not been fully elucidated. Thus, we hypothesized that additional mechanisms are likely operative that induce EZH2 upregulation in prostate cancer, at least during the early phases of the disease.

MYC is one of the most commonly overexpressed oncogenes in cancer [14]. In prostate cancer, Myc overexpression is a frequent and early event, occurring in lesions of both high grade prostatic intraepithelial neoplasia (PIN), and localized and metastatic prostatic adenocarcinomas, suggesting that Myc contributes to the initiation and progression of the disease [15]. Myc is a pleiotropic transcription factor which is key in controlling the expression of genes involved in DNA replication, protein synthesis, cell cycle progression, cellular metabolism, chromatin structure, differentiation and stem cell fate $[14,16]$. It was previously shown that Myc can activate and repress the expression of numerous miRNAs [17-20], hence providing additional mechanisms by which Myc can control gene expression. Studies carried out in lymphoma cells and hepatocelluar carcinoma cells have shown that Myc represses the expression of a number of miRNAs, including miR-26a and miR-26b [17, 21]. Interestingly, the 3'UTR of EZH2 contains target sites for miR-26a and miR-26b, and EZH2 was shown to be targeted for repression by miR-26a in muscle and lymphoma cells [21, 22], and of miR-26b in HeLa cells [23]. Hence, we hypothesized that Myc may be a key driver of EZH2 overexpression in PIN and prostate cancer lesions via repression of miR-26a and miR-26b. Further, since Myc is a well-known sequence specific transacting factor that binds to promoter regions and regulates transcription of a relatively large number of target genes, we also investigated whether Myc can directly transactivate EZH2 transcription as well.

\section{MATERIALS AND METHODS}

\section{Animal studies}

The experimental protocol was approved by the Animal Care and Use Committee at Johns Hopkins University, and the animals were cared for in accordance with institutional guidelines. The Lo-MYC transgenic mice used in this study were obtained from the Mouse Repository of the National Cancer Institute Mouse Models of Human Cancer Consortium at NCI Frederick, MD, USA, and were maintained as previously described [24].

\section{Cell Culture}

The human prostate cancer cell lines LNCaP, CWR22rv1, DU145 and PC3, were obtained from the American Type Culture Collection (ATCC). MYC-CaP cells were a generous gift from Charles Sawyers [25]. They were maintained at $37^{\circ} \mathrm{C}$ and $5 \% \mathrm{CO}_{2}$, and supplemented with RPMI 1640 or DMEM with 10\% serum.

\section{Transfections}

Cells were transfected using Oligofectamine or Lipofectamine 2000 (Invitrogen). MYC siRNA pools (Dharmacon, L-003282), siCONTROL Non-Targeting siRNA pool \#1 (Dharmacon, D-001810), miRIDIAN Mimic hsa-mir-26a (Dharmacon, C-300499), miRIDIAN Mimic hsa-mir-26b (Dharmacon, C-300501) and miRIDIAN microRNA Mimic Negative Control \#1 (Dharmacon CN-001000) were transfected at a final concentration of $50 \mathrm{nM}$.

\section{Quantitative Real-time PCR}

RNA was isolated from cells using miRNeasy kit (Qiagen), and from tissue sections using Trizol (Invitrogen). cDNA was synthesized using the RetroScript kit (Ambion). Quantitative RT-PCR was carried out using iQ SYBR Green Supermix (Biorad). PCR primers are shown in Supplementary Table 1. The relative amount of the gene of interest was determined using the $\Delta \Delta C_{t}$ method, relative to TBP and to the control cells, or matched normal tissue. Mature miR-26a and miR-26b expression was measured by Taqman assay (Applied Biosystems) according to manufacturer's instructions, and normalized against U6 expression. Four independent knockdown experiments were carried out, and triplicate quantitative PCR experiments were done for each condition. Data was $\log _{2}$ transformed and error bars represent the standard deviation.

\section{Western Blotting}

Cells and tissues were lysed in RIPA buffer and stored at $-80^{\circ} \mathrm{C}$. Lysates were separated on SDS-PAGE gels and electrophoresed onto PVDF membranes. Membranes were probed with antibodies against EZH2 (Epitomics, 1:2000) and tubulin (Calbiochem CP06, 1:2000) in 5\% non-fat dry milk in TBST.

\section{Chromatin Immunoprecipitation}

ChIP was carried out using the rabbit polyclonal anti-MYC antibody (Santa Cruz, sc-764), as previously 
described [26]. Primers are listed in Supplementary Table 1.

\section{Cell Proliferation Assays}

Cells were stained with $0.4 \%$ trypan blue, and the number of viable cells was counted using a hemocytometer.

\section{Luciferase Reporter Assays}

The complete and truncated EZH2 3' UTR were amplified using the primers listed in Table S1. They were cloned into the pMIR-REPORT ${ }^{\mathrm{TM}}$ miRNA Expression Reporter Vector System (Ambion) between the HindIII and SpeI sites. The EZH2 promoter reporter vector
(S111151) was purchased from SwitchDB. The reporter promoters were transfected along with a Renilla control plasmid, and either non-targeting siRNA, MYC siRNA, miR-26a mimics, or miR-26b mimics. Luciferase activity was measured 24 hours after transfection using the Dual-luciferase reporter assay system (Promega). Three independent experiments were carried out, with 4 replicates for each condition.

\section{Immunohistochemistry (IHC)}

Immunohistochemistry was done with the Power Vision+ poly-HRP IHC Kit (ImmunoVision Inc). Slides were steamed for 40 minutes in EDTA solution (Zymed) and incubated with mouse anti-EZH2 antibody (BD

\section{A FVB - Non-transgenic}
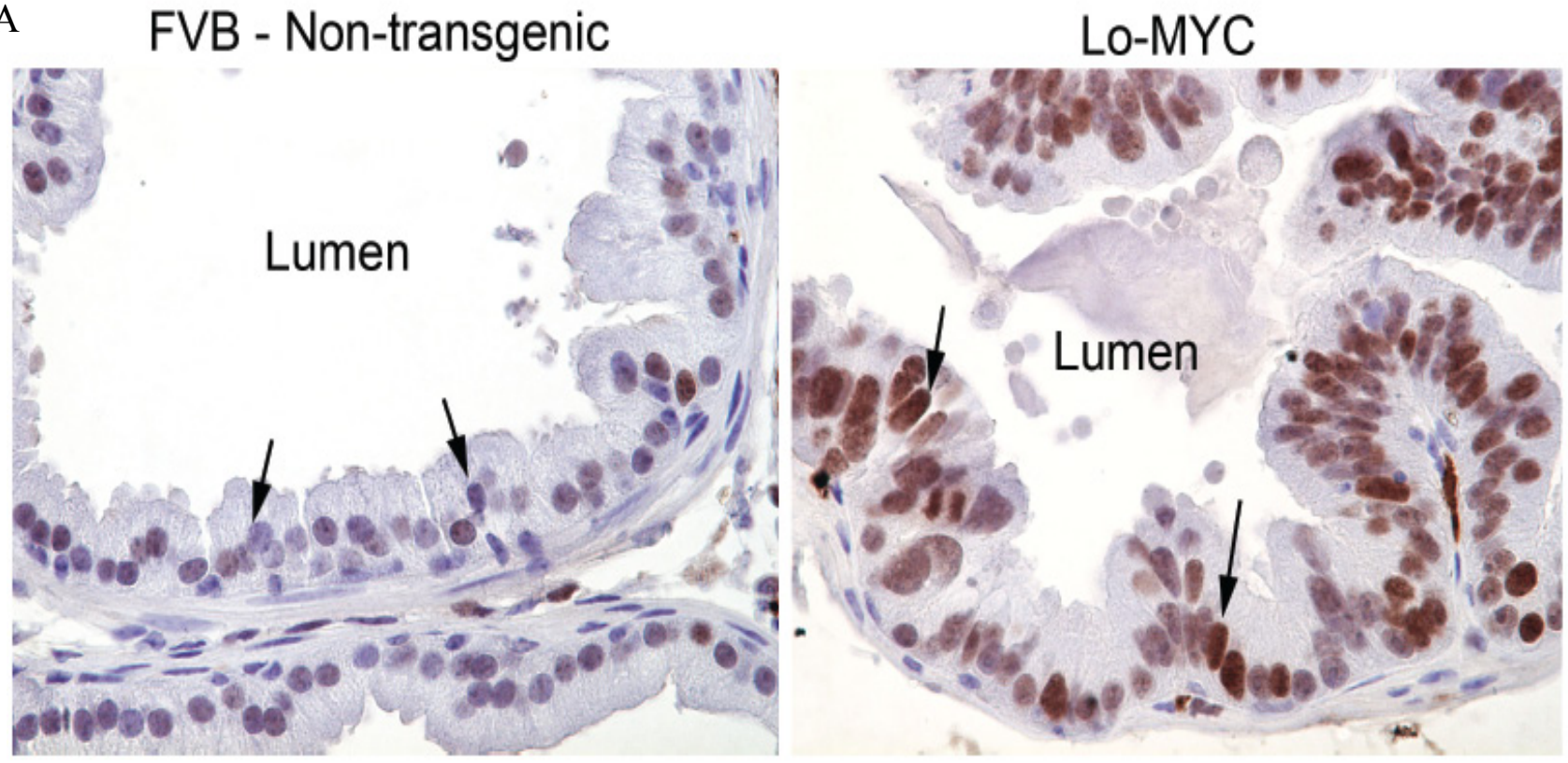

B

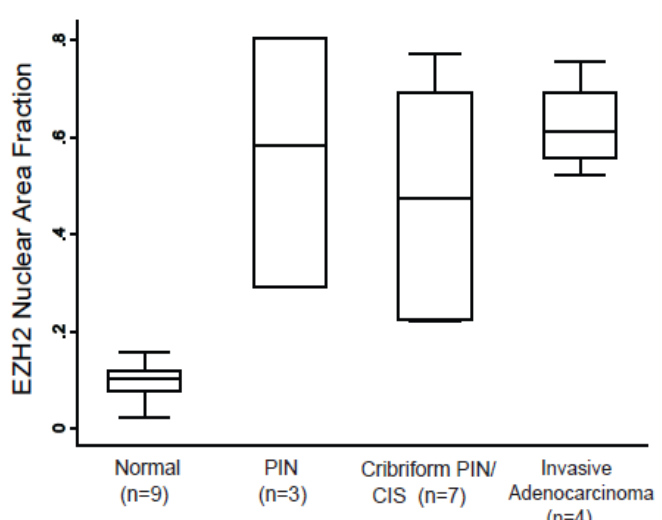

$\mathrm{C}$

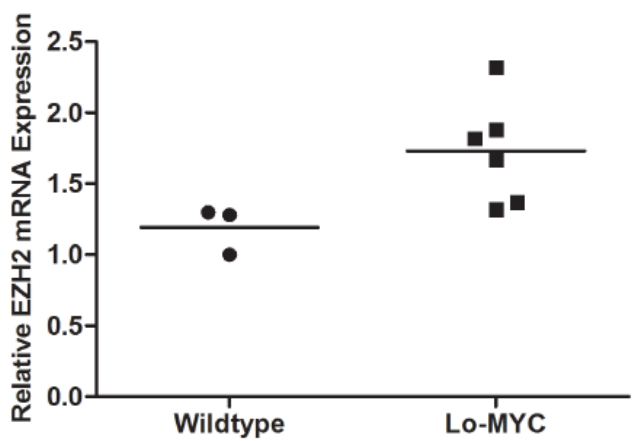

Figure 1: Elevated EZH2 Expression in the Lo-MYC Murine Model of Prostate Cancer. $(A)$ Increased EZH2 protein expression in the ventral prostates of Lo-MYC mice (right panel), as compared to wild type controls (left panel). (B) Semi-quantitative image analysis of EZH2 protein expression in 9 wild type and 14 Lo-MYC mice. EZH2 expression was elevated in PIN, cribriform PIN/ CIS, and invasive adenocarcinoma lesions, as compared to normal prostate. (C) EZH2 mRNA is elevated in PIN lesions from the ventral prostates of Lo-MYC (6 mice), as compared to ventral prostates from age-matched wildtype FVB mice (3 mice). 
Transduction) overnight. Poly-HRP-conjugated antimouse/rabbit IgG antibody was used as secondary antibody. Staining was visualized using 3,3'-Diaminobenzidine (Sigma) and slides were counterstained with hematoxylin.

\section{Quantitative Image Analysis}

Scanned images were analyzed using FriDA as previously described [15].

\section{Tissues}

This study was approved by The Johns Hopkins University School of Medicine institutional review board. Matched normal and tumor pairs were obtained from frozen sections from radical prostatectomy specimens. Specimens comprised Gleason scores 6 and 7, and stages from T2N0Mx to T3BN0Mx (Table S2).

\section{Statistics}

Students t-test was performed to determine statistical significance and p-values are indicated in the text. Changes are also indicated in the figures where $(*)$ represents $\mathrm{p}<0.05$.

A

Case1 Case2 Case3 Case4 Case5

\section{$\begin{array}{llllllllll}\mathbf{N} & \mathbf{T} & \mathbf{N} & \mathbf{T} & \mathbf{N} & \mathbf{T} & \mathbf{N} & \mathbf{T} & \mathbf{N} & \mathbf{T}\end{array}$}

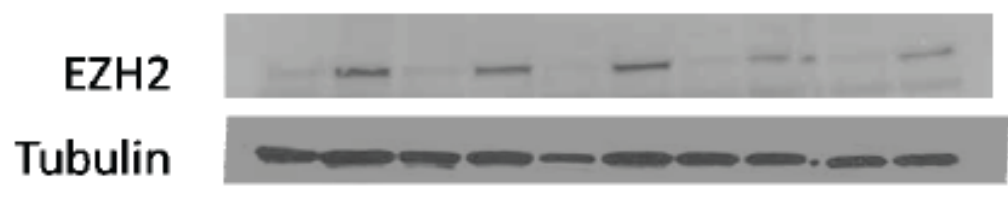

B
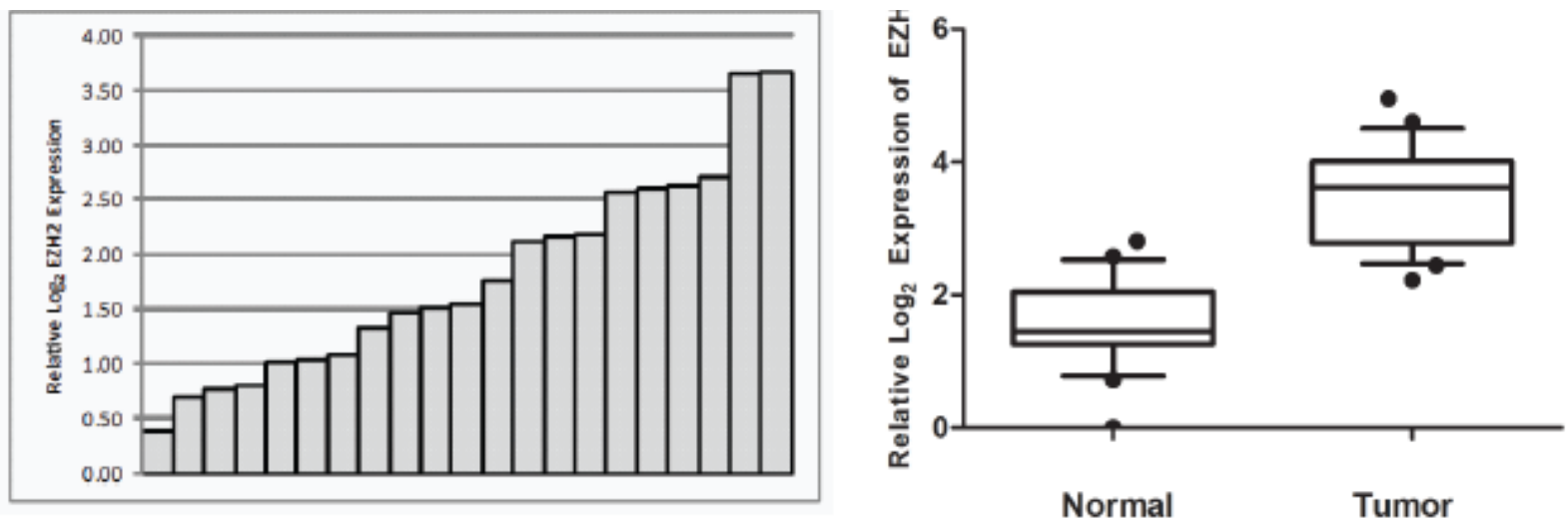

C

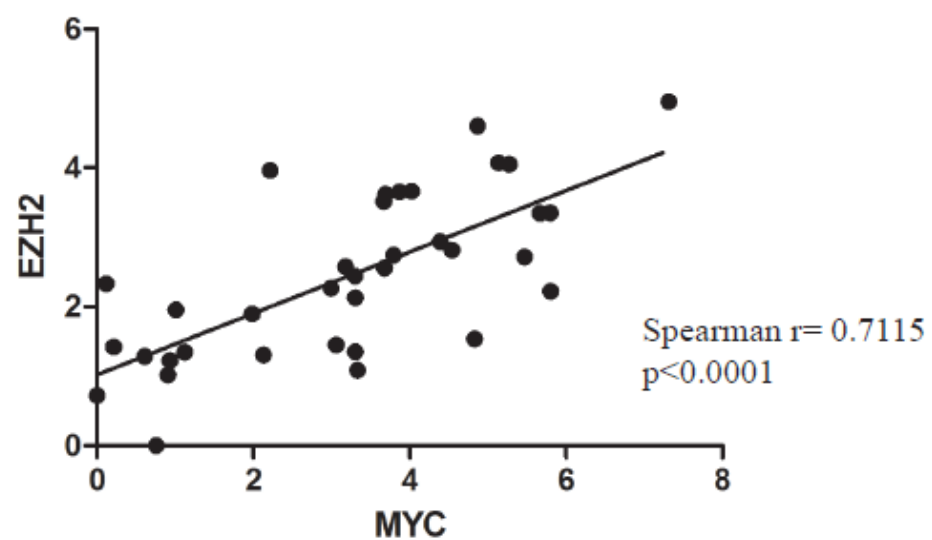

Figure 2: Correlation between MYC and EZH2 expression in primary prostate cancer specimens. $(A)$ Western blot showing increased EZH2 protein expression in localized prostate cancer specimens, as compared to matched normal tissue. $(B)$ Elevated EZH2 mRNA levels in localized prostate cancer specimens, as compared to matched normal tissue, determined by quantitative real-time PCR. (C) Positive correlation between the expression of MYC and EZH2 mRNA levels. 


\section{MYC regulates EZH2 in the Lo-MYC murine model of prostate cancer}

The Lo-MYC transgenic mouse model recapitulates the molecular and histological phenotype of early human prostate cancer formation [24, 27]. In this model, Myc overexpression in the prostate induces the morphologically distinguishing features of PIN, including nuclear and nucleolar enlargement, an increase in mitotic figures, as well as widespread chromatin remodeling. Using these mice for immunohistochemical staining, we observed that the expression of EZH2 protein was barely detectable in control non-transgenic littermate mice, but that levels were markedly upregulated in PIN lesions in the LoMYC mice (Fig. 1A). Similar to overexpression of Myc,
A

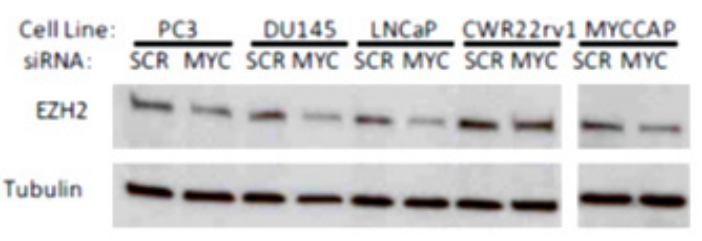

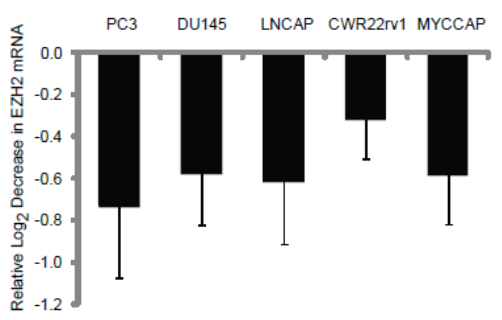

B
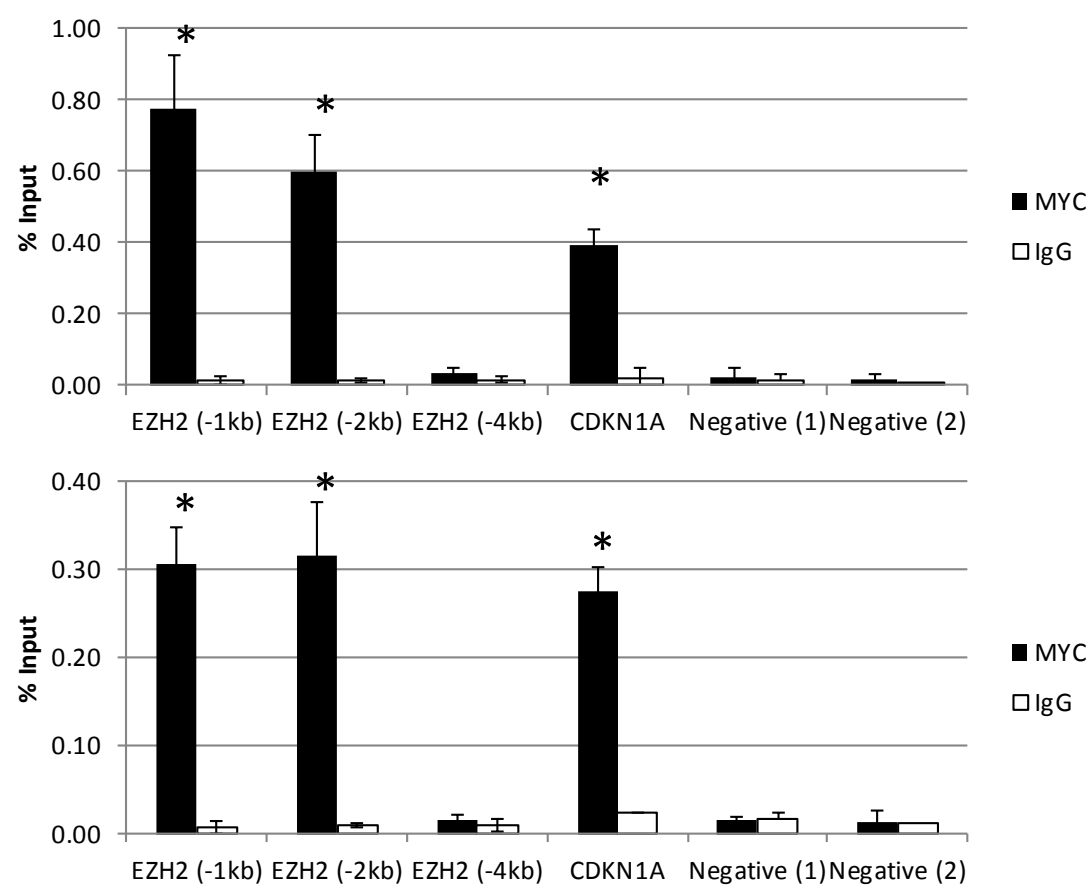

$\mathrm{C}$

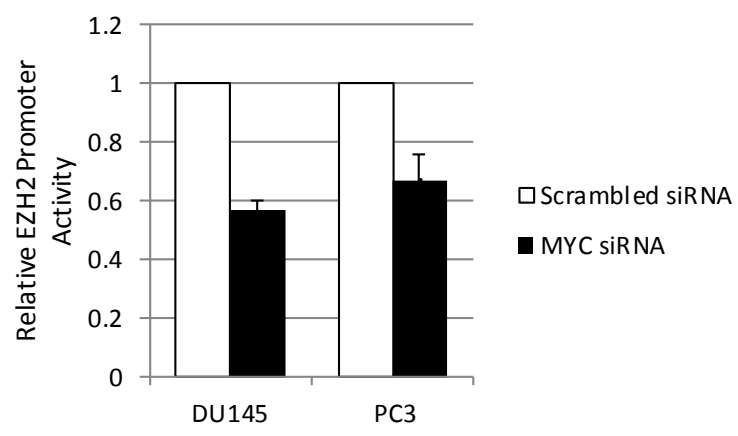

Figure 3: Myc binds to the EZH2 promoter region and activates EZH2 transcription in prostate cancer cell lines. (A) Reduced EZH2 protein (Left Panel) and mRNA (Right Panel) expression following siRNA-mediated MYC depletion. (B) Enrichment of Myc binding at the E-box-containing promoter region of EZH2 in 2 prostate cancer cell lines, as determined by ChIP. Immunoprecipitation was carried out with an anti-Myc antibody (black bars) and a control IgG antibody (white bars). (C) Decreased EZH2 promoter activity after MYC depletion (black bars), as compared to control cells (white bars) in human prostate cancer cell lines. 
the increased expression of EZH2 protein in PIN lesions was confined to luminal epithelial cells. Semi-quantitative image analysis showed that as compared to wild-type mice, there was a marked increase in expression of EZH2 in PIN lesions, cribriform PIN lesions and early invasive adenocarcinoma lesions in the transgenic mice (Fig. 1B). Similar results were obtained in a number of Hi-MYC mice (not shown). Next, used quantitative real time RTPCR and found that EZH2 mRNA was also increased in the Myc-overexpressing transgenic mice, compared to the wild type controls (Fig. $1 C, \mathrm{p}<0.03$ ). Thus, in these Mycdriven murine models of prostate cancer, EZH2 elevation occurs downstream of Myc induction.

\section{MYC and EZH2 are overexpressed in primary prostate cancer specimens}

It has been shown that EZH2 is overexpressed in prostate cancer, particularly in aggressive metastatic cases [6]. We prepared crude whole cell lysates from 5 matched benign and primary prostate cancer specimens and verified that EZH2 protein expression was elevated in the tumors (Fig. 2A). Next, we obtained mRNA from 18 matched normal and primary prostate cancer specimens (Table S2) and confirmed that MYC and EZH2 mRNA were indeed overexpressed in the prostate cancers (Wilcoxon signed ranked test, $\mathrm{p}<0.0002$ for both) (Fig. $2 B, \mathrm{~S} 1 A$ ). Additionally, in these same specimens there was a significant positive correlation between $M Y C$ and EZH2 mRNA expression (Spearman rank correlation coefficient $=0.7115, \mathrm{p}<0.0001)($ Fig. $2 C)$.

\section{MYC regulates EZH2 $\mathrm{mRNA}$ and protein expression in prostate cancer cell lines}

We used siRNA-mediated knockdown to deplete Myc in 4 human prostate cancer cell lines- DU145, PC3, LNCaP and CWR22rv1, as well as in the MYC$\mathrm{CaP}$ cell line, which was derived from the Hi-MYC transgenic mouse model [25]. We have recently shown approximately $50-70 \%$ of Myc protein could be reduced using these siRNA transfection conditions in each of these cell lines [28]. 72h after Myc knockdown, we measured the expression of EZH2 mRNA by quantitative real time PCR, relative to the expression of $T B P$, and found it to be reduced by $30 \%-60 \%(\mathrm{p}<0.05)$ (Fig. $3 A$, right panel). Accordingly, as compared to control cells that were transfected with non-targeting siRNA, EZH2 protein was also reduced in cells that had been transfected with siRNA targeting Myc (Fig. 3A, left panel). By microarray analyses, we observed an induction of $C D H 1$ and $A D R B 2$, known EZH2 target genes, following MYC depletion in LNCaP and DU145 cells (Fig. S1B).

By examining publically available data in the UCSC genome browser database, Myc was observed to associate upstream of the EZH2 transcription start site in K562 human myelogenous leukaemia cells and GM12878 lymphoblastoid cells (Figure S1C). To address whether EZH2 is a direct target of transcriptional activation by Myc in prostate cancer, we carried out chromatin immunoprecipitation (ChIP), and enriched Myc binding approximately $1 \mathrm{~kb}$ and $2 \mathrm{~kb}$ upstream of the transcription start site of EZH2, which contains a canonical E-box (Figure $3 B$ ). With increasing distance upstream of the EZH2 transcription start site (approximately $-4 \mathrm{~kb}$ ), there was no significant enrichment of Myc binding. To determine if EZH2 is a direct MYC target gene, we used firefly luciferase as a reporter of EZH2 promoter activity. In DU145 and PC3 cells that had been depleted of MYC by siRNA-mediated knockdown, we observed reduced EZH2 promoter activity (Fig. $5 B ; \mathrm{p}<0.02$ for both cell lines),indicating that MYC can indeed activate EZH2 transcription in prostate cancer cell lines.

\section{Myc represses miR-26a and miR-26b expression}

Myc was previously reported to regulate the expression of miRNAs [17], including miR-26a and miR-26b in P493 lymphoma cells, by direct binding to their host Pol II gene promoters (CTDSPL, CTDSP2, $C T D S P 1)$. However, such regulation has not been evaluated in prostate cancer. Since regulation of target genes by Myc can be cell type and context specific, we determined whether similar mechanisms were operative in prostate cancer cells. siRNA-mediated MYC depletion in 4 human prostate cancer cell lines was followed by quantitative real-time PCR to measure the expression of the mature miR-26a, its 2 primary forms, mir-26a1, and mir-26a2, as well as the host genes in which they are embedded, CTDSPL and CTDSP2. Additionally, we measured the expression of the mature and primary forms of miR-26b, and CTDSP1, the gene which harbors miR26b. Following MYC-depletion, we found a coordinate increase in the mRNA levels of CTDSPL, CTDSP2 and $C T D S P 1$, and both the mature and primary forms of miR$26 \mathrm{a}$ and miR-26b in all 4 cell lines ( $\mathrm{p}<0.02$ for all) (Fig. $4 A$ ). To determine if MYC may be directly regulating miR$26 \mathrm{a}$ via repression of $C T D S P L$ and $C T D S P 2$, and miR$26 \mathrm{~b}$ via repression of $C T D S P 1$, we carried out chromatin immunoprecipitation on LNCaP and PC3 cells. We found a significant enrichment of $\mathrm{MYC}$ at the promoters of CTDSPL, CTDSP2 and CTDSP1 in both prostate cancer cell lines (Fig. 4B). MYC was previously reported to associate with these promoters in P493 lymphoma cells [17]. In terms of Lo-MYC mice, we found that levels of both miR-26a and miR-26b were reduced in PIN lesions as compared to normal epithelium in wild type controls ( $\mathrm{p}<0.0005$ for both) (Fig. 4C). Further, miR-26a and miR$26 \mathrm{~b}$ expression was increased in MYC-CaP cells after MYC depletion ( $\mathrm{p}<0.02$ for both) (Fig. 4D). Therefore, the regulation of these miRNAs by MYC occurs in both 
mouse and human prostatic cancer cells.

\section{$\mathrm{EZH2}$ is a target of miR-26a and miR-26b in prostate cancer}

Previous work in muscle, lymphoma and HeLa cells have shown that miR-26a and miR-26b can negatively regulate EZH2 expression, and that this occurs via binding to the highly conserved predicted miR-26a/b binding site within the 3' UTR of EZH2 [21-23]. However, miR-26a did not regulate EZH2 in breast cancer or acute myeloid leukemia cells $[5,29]$, indicating that miRNA-regulation of target gene expression may be tissue and/or context specific. To determine if mir-26a and miR-26b can target EZH2 in prostate cancer cells, we transfected miR-26a and miR-26b mimics into one mouse and four human prostate cancer cell lines. We observed a reduction in EZH2 mRNA
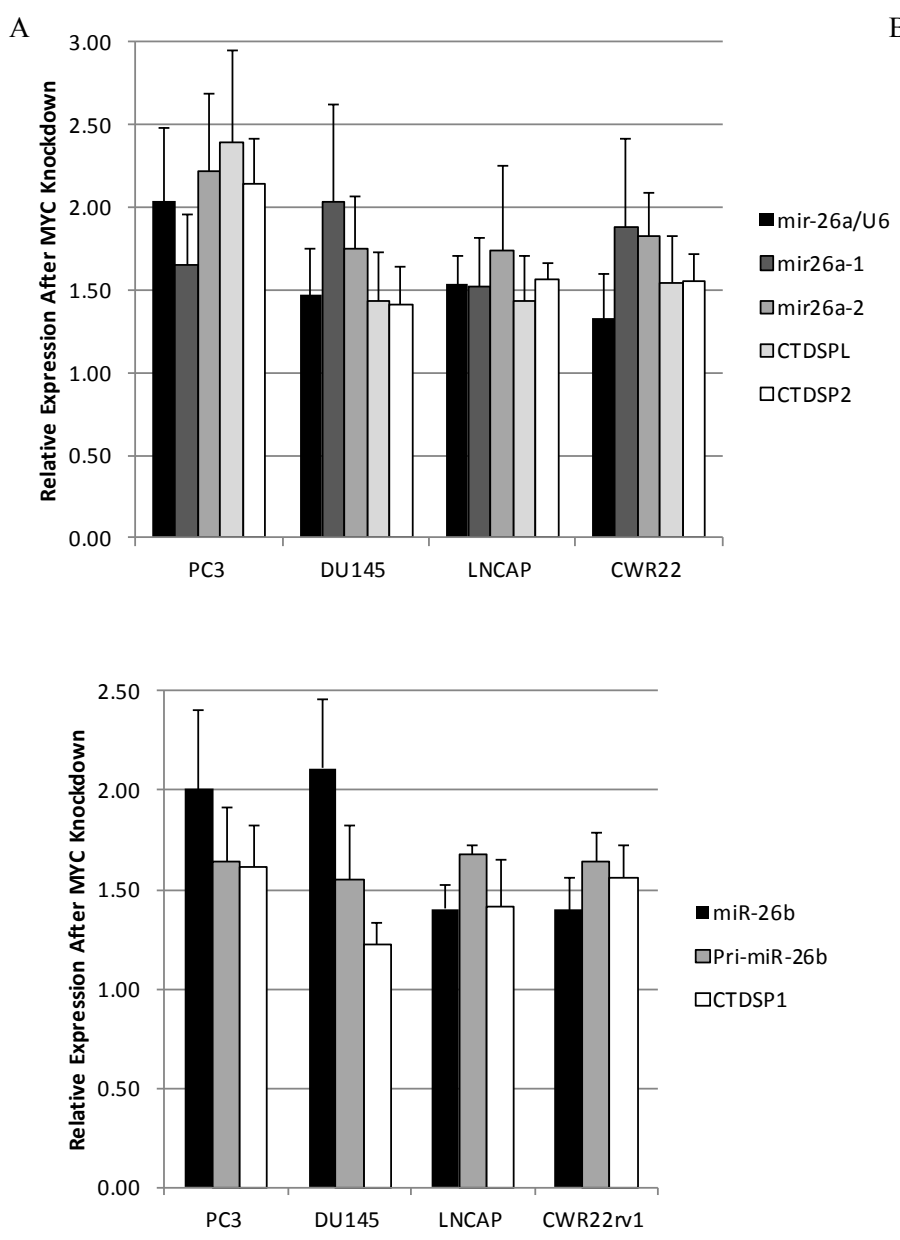

levels in all 5 cell lines $(\mathrm{p}<0.05)$, and a similar decrease in $\mathrm{EZH} 2$ protein following transient overexpression of miR-26a and miR-26b (Fig 5A, $B$ ). In the Lo-MYC mouse model, there was a significant negative correlation between the expression of EZH2 mRNA and miR-26a (Spearman rank correlation coefficient $=-0.8667, \mathrm{p}=0.0045)$, as well as EZH2 mRNA and miR-26b (Spearman rank correlation coefficient $=-0.8167, \mathrm{p}=0.0108$ ) (Fig. S2A). To verify specific associations between miR-26a and miR-26b and their predicted binding site on the EZH2 3'UTR in prostate cancer cells, we cloned the 3'UTR of EZH2 into a luciferase reporter vector [21]. Co-transfection with either miR-26a mimics, miR-26b mimics or Myc siRNA resulted in reduced reporter activity, as compared to transfection with a non-targeting $\mathrm{miR}(\mathrm{p}<0.03)$ (Fig. $5 C$ ). As an additional control, we generated a luciferase reporter vector with a truncated EZH2 3'UTR, which lacks the miR-26a/b binding site. Using this construct,
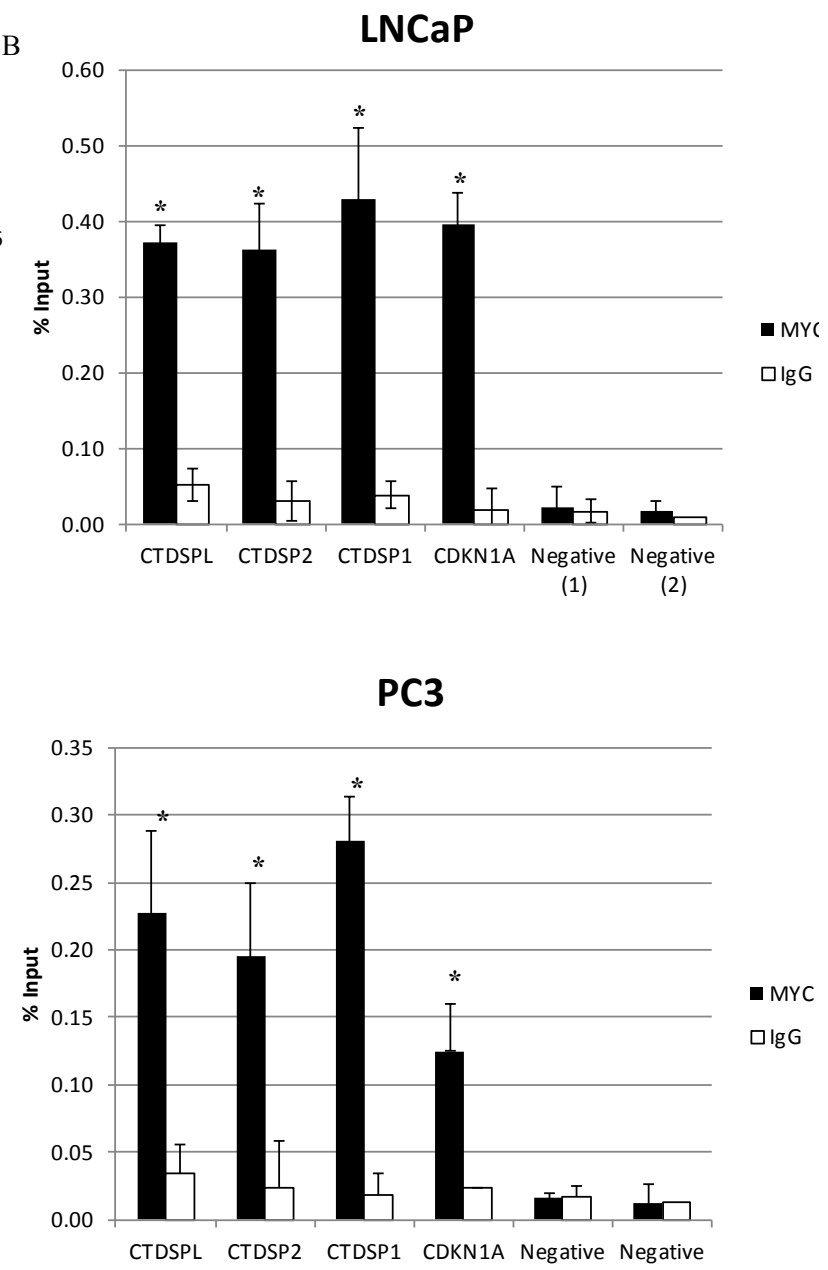

(1)

(2)

Figure 4: Myc Regulates miR-26a and miR-26b in Human and Murine Prostate Cancer Cells. ( $A$ ) (Upper Panel) Induction of miR-26a, its primary forms miR-26al and miR-26a2, and the genes in which they are embedded, CTDSPL and CTDSP2, following siRNA-mediated Myc depletion. (Lower Panel) Induction of miR-26b, its primary form, and the gene in which it is embedded, CTDSP1. $(B)$ Enriched Myc binding was observed at the promoter regions of CTDSPL, CTDSP2 and CTDSP1. Immunoprecipitation was carried out with an anti-Myc antibody (black bars) and a control IgG antibody (white bars). (C) Reduced miR-26a (Left Panel) and miR-26b (Right Panel) expression in the Lo-MYC mice, as compared to wildtype controls. $(D)$ Induction of miR-26a and miR-26b after Myc depletion in MYC-CaP cells. 
there was no significant reduction in reporter activity following co-transfection with miR-26a mimics, miR$26 \mathrm{~b}$ mimics or Myc siRNA (Fig. 5C). There was also was an induction of $C D H 1$ and $A D R B 2$, known EZH2 target genes, following miR-26a and miR-26b overexpression in LNCaP cells (Fig. S2B).

To determine the biological relevance of miR$26 \mathrm{a}$ and $\mathrm{miR}-26 \mathrm{~b}$ in prostate cancer cells, we assessed the effect of miR-26a and miR-26b transfection on the proliferation of 4 human prostate cancer cell lines and the Myc-driven mouse prostate cancer cell line. In all cell lines, proliferation was suppressed $(\mathrm{p}<0.01)$ (Fig. 5D). This suggests that Myc-mediated repression of miR-26a and miR-26b may be an important factor in maintaining the proliferative capacity of prostate cancer cells.

\section{MYC, EZH2 and miR-26a expression in localized prostate cancer samples.}

Next, to determine the relevance of miR-26a and miR-26b in clinical prostate cancer, we measured their expression in 18 matched normal and primary prostate cancer specimens (Table S2) and found both to be downregulated in cancer in most cases (Wilcoxon signed rank test, $\mathrm{p}=0.0005$ for $\mathrm{miR}-26 \mathrm{a}, \mathrm{p}=0.079$ for miR-26b) (Fig. 6A, Fig. S3A). There was a significant inverse correlation between the expression of $M Y C$ and miR-26a (Spearman rank correlation coefficient $=-0.357$, $\mathrm{p}=0.032$ ), while that for $M Y C$ and miR-26b did not achieve statistical significance (Fig. 6B, Fig. S3B). We also observed significant inverse correlations between miR-26a and EZH2 mRNA (Spearman rank correlation coefficient $=-0.516, \mathrm{p}=0.0013$ ), and $\mathrm{miR}-26 \mathrm{~b}$ and $E Z H 2$ mRNA (Spearman rank correlation coefficient $=-0.3552$, p<0.0392) (Fig. 6C, Fig. S3C).

\section{DISCUSSION}

EZH2 mRNA and protein levels are elevated during progression of a number of types of cancer, including breast and prostate cancer [6, 30-32]. Further, several studies have shown oncogenic activity for EZH2 in a range of tumor cell types $[2,9,33]$. Prior to the present study, three molecular mechanisms were identified that could be responsible for overexpression of EZH2 in prostate cancer--amplification of the EZH2 gene [8], the deletion of its negative regulator miR-101 [5], and transcriptional regulation of EZH2 by ETS gene family members [12,

$\mathrm{C}$
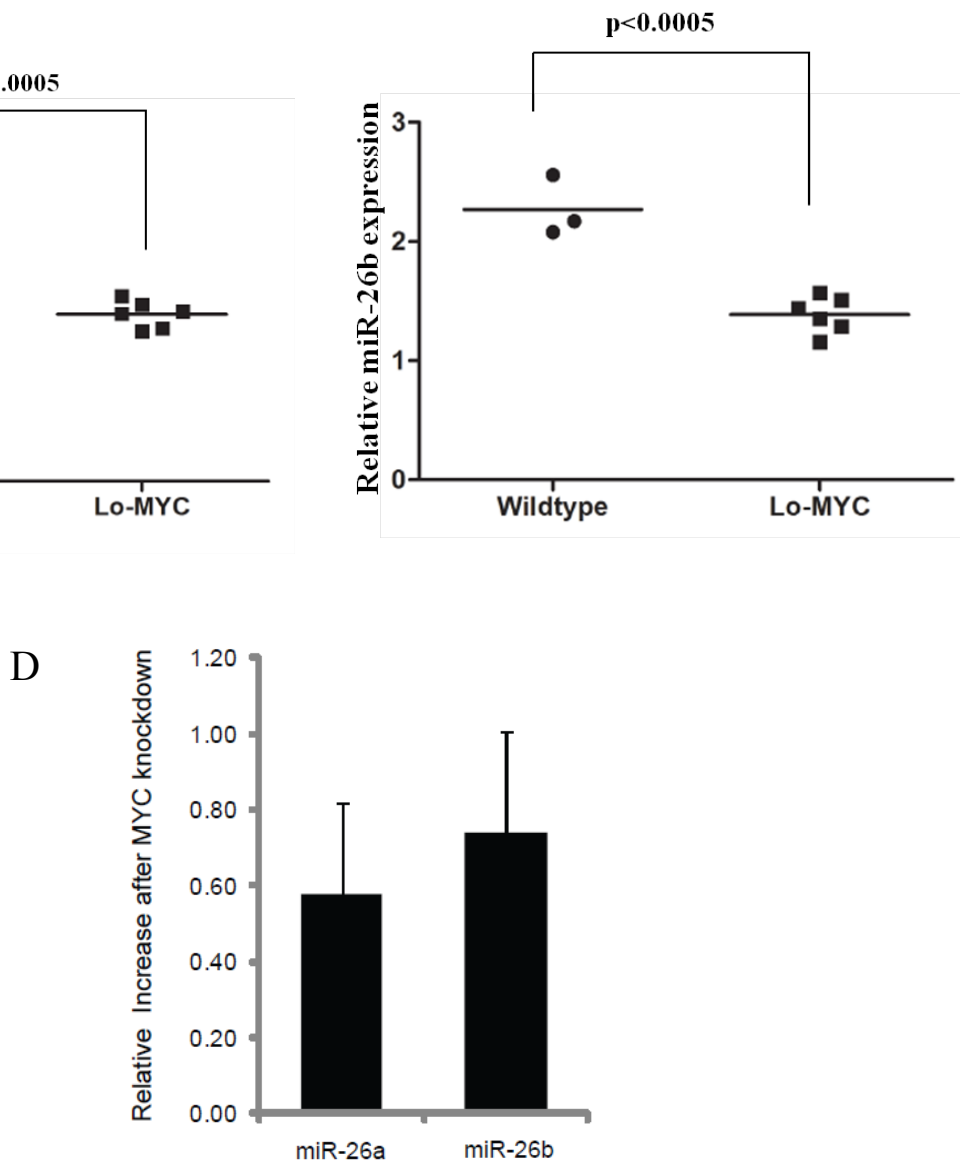

Figure 4: Myc Regulates miR-26a and miR-26b in Human and Murine Prostate Cancer Cells. $(C)$ Reduced miR-26a $(L e f t$ Panel) and miR-26b (Right Panel) expression in the Lo-MYC mice, as compared to wildtype controls. (D) Induction of miR-26a and miR$26 \mathrm{~b}$ after Myc depletion in MYC-CaP cells. 
13]. Interestingly, two of these mechanisms (EZH2 amplification and miR-101 deletion) are encountered more frequently in advanced and castrate resistant prostate cancers than in primary untreated prostate cancers, and ETS family gene fusions and ERG protein overexpression are rarely seen in isolated PIN lesions or PIN lesions associated with ERG-negative carcinomas [34]. While EZH2 elevation is most marked in advanced/ castrate resistant metastatic lesions, EZH2 is also very commonly overexpressed in almost all human PIN and early prostate cancer lesions [6]. Whether EZH2 overexpression is also regulated by other mechanisms in PIN and primary prostate cancer lesions has not previously been examined. Here, we show that Myc induces overexpression of EZH2 by two independent yet complementary mechanisms, and that this overexpression is seen in PIN lesions in Lo-MYC and Hi-MYC mice, as well as in human tissue samples. Since Myc is commonly overexpressed in human PIN and early carcinoma lesions, it is likely that overexpression of Myc is a key driver of EZH2 overexpression during the early phases of prostate cancer formation. Additionally, since Myc is also overexpressed, and commonly shows elevated gene copy number in advanced/hormone refractory prostate cancers, these results also provide additional mechanisms by which EZH2 overexpression may occur and/or be maintained at this stage of the disease.

Using 5 prostate cancer cell lines (4 human, 1 mouse), we showed that Myc depletion by siRNA results in decreased EZH2 mRNA and protein. It was previously reported that p53 can suppress EZH2 [35], and that E2F can induce $E Z H 2$ [36], but little is otherwise known about the direct transcriptional regulation of EZH2. Using ChIP,

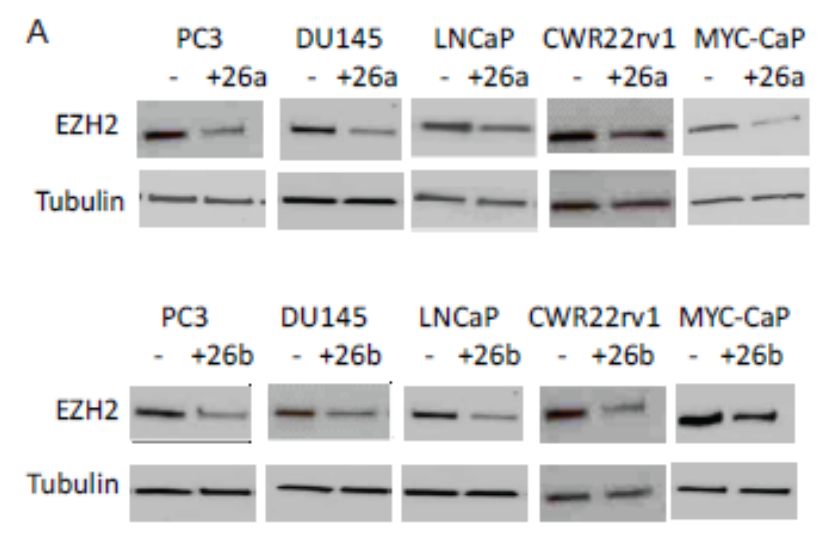

B
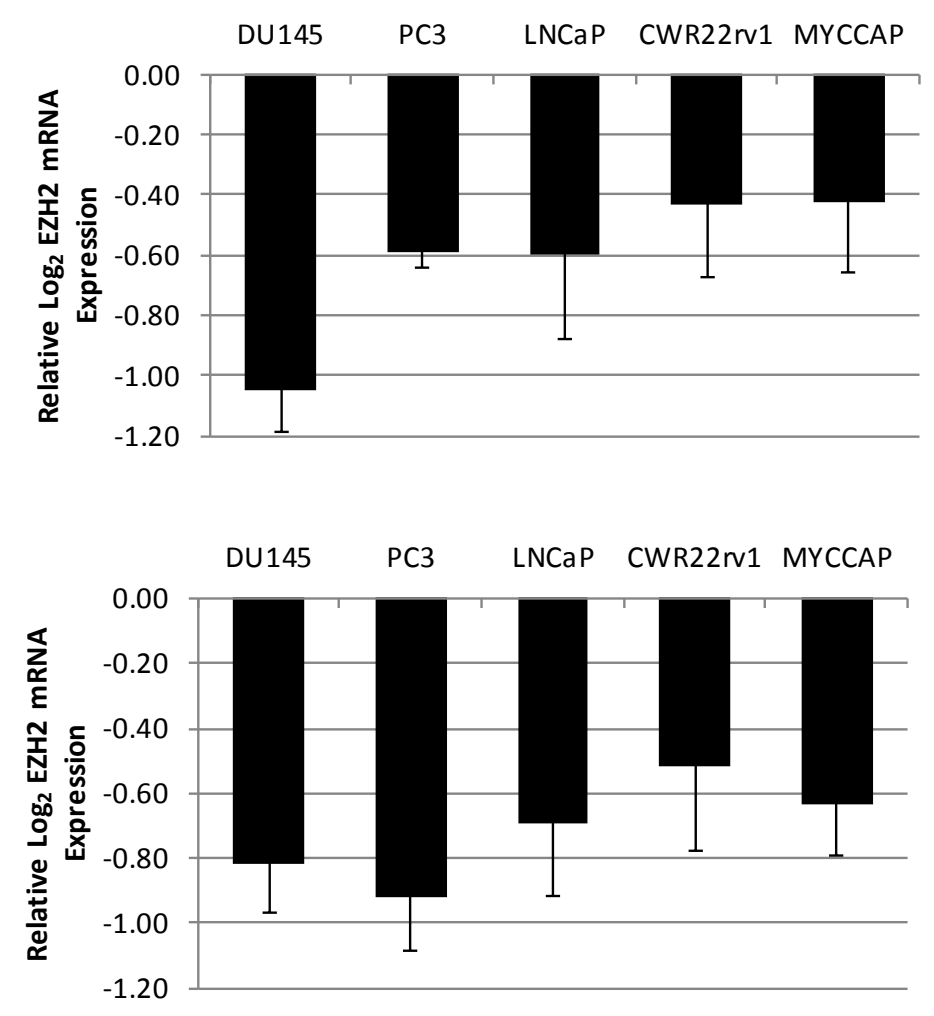

Figure 5: MiR-26a and miR-26b Regulate EZH2 Expression in Human and Murine Prostate Cancer Cells. $(A, B)$ MiR26a and miR-26b repress EZH2 protein $(A)$ and mRNA $(B)$ expression. 
we determined in 2 prostate cancer cell lines that MYC directly associates with the E-box-containing promoter region of EZH2. While this manuscript was in process, Salvatori et al. reported similar findings in acute myeloid leukemia, showing that Myc directly binds upstream of EZH2 and activates its transcription [29]. While EZH2 expression was shown to regulate MYC expression in a glioma tumor model [37], it is clear in the Lo-MYC mouse model that $\mathrm{MYC}$ is elevated prior to $\mathrm{EZH} 2$ overexpression.

Since Myc is known to regulate miRNAs, in addition to mRNAs, we sought to determine Myc -responsive miRNAs in prostate cancer. MiR-26a and miR-26b have been reported to be Myc-repressed in lymphoma cells [17, 21]. By quantitative real-time PCR, we found that Myc represses miR-26a and miR-26b in all prostate cancer cell lines studied. Additionally, we observed decreased miR$26 \mathrm{a}$ and miR-26b expression in the Lo-MYC mice, as compared to the wildtype controls. In LNCaP and PC3 cells, we observed an enrichment of Myc binding at the promoter regions of CTDSPL, CTDSP2 and CTDSP1, genes whose introns harbor the miR-26a and miR-26b primary transcripts. EZH2 is a reported target of miR$26 \mathrm{a}$ in muscle and lymphoma cells $[21,22]$, and of miR$26 \mathrm{~b}$ in HeLa cells [23]. In prostate cancer cells, we found that both miR-26a and miR-26b repressed both EZH2 mRNA and protein. Further, using heterologous reporter constructs we found that the conserved miR-26a/b binding site within the 3' UTR of EZH2 was required for this repression. As such, Myc may contribute to EZH2

$\mathrm{C}$

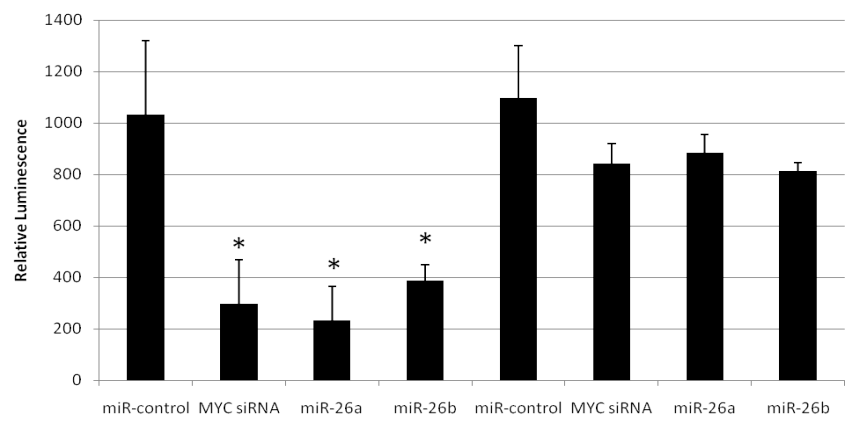

Luc(EZH2 3'UTR) L Luc(EZH2 3'UTR -miR binding site)

DU145

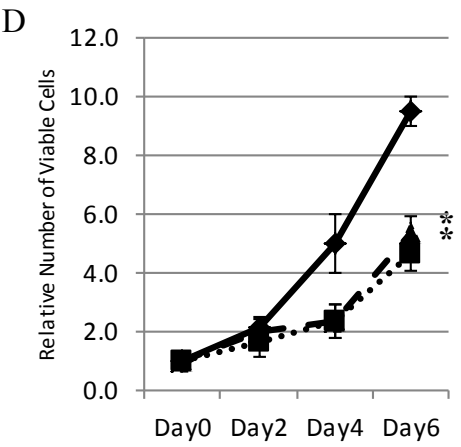

CWR22rv1

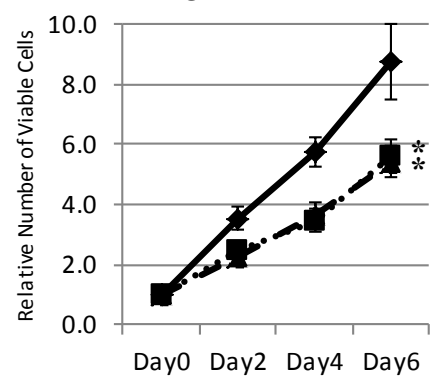

PC3

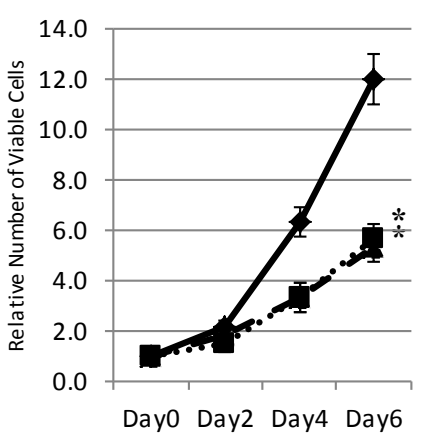

MYCCaP

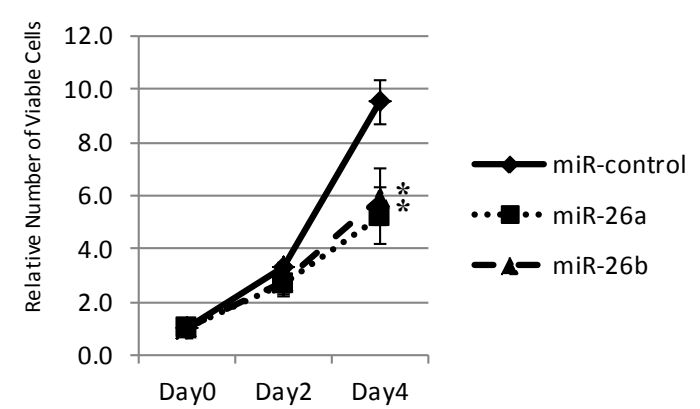

LNCaP

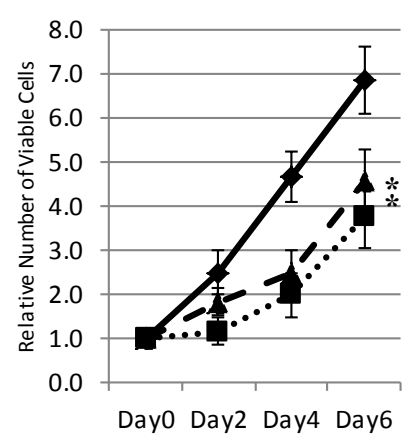

Day0 Day2 Day4 Day6

Figure 5: MiR-26a and miR-26b Regulate EZH2 Expression in Human and Murine Prostate Cancer Cells. $(C)$ miR-26a and miR-26b bind to the 3'UTR of EZH2 in prostate cancer cells. $(D)$ Reduced proliferation of prostate cancer cell lines after transfection with miR-26a (dotted lines) and miR-26b (dashed lines), as compared to control miR (solid lines). 
elevation in prostate cancer, by directly activating $E Z H 2$ transcription, and by repressing its negative regulators, miR-26a and miR-26b. Previously, Cao et al. reported that overexpression of miR-26a reduced EZH2 expression in DU145, but not PC3 or LNCaP cells, even though miR-26a inhibited the expression of a reporter construct containing the 3'UTR of EZH2 in all three cell lines [38]. This somewhat discrepant finding from ours may be a result of different transfection conditions or time points at which samples were harvested.

In our set of matched primary prostate cancer

A

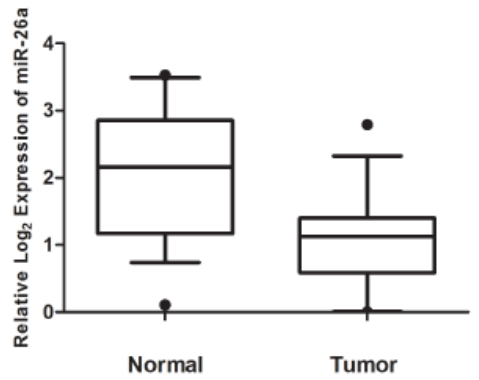

Wilcoxon signed rank test, $\mathrm{p}=0.0005$

B

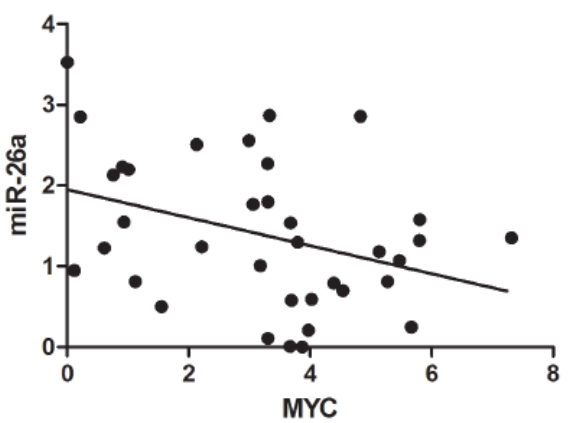

Spearman rank correlation coefficient $=-0.357$, $\mathrm{p}=0.032$

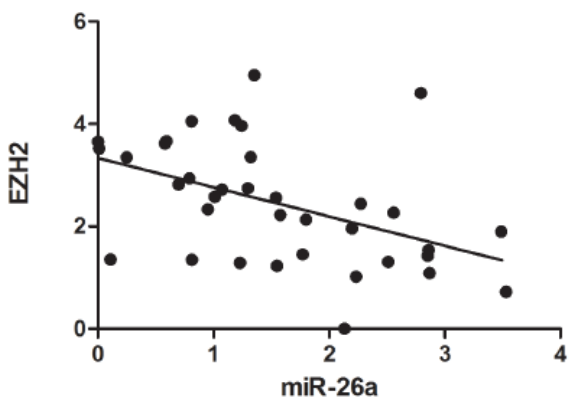

Spearman rank correlation coefficient $=-0.516$, $\mathrm{p}=0.0013$ specimens and normal prostate tissue, we found $M Y C$ and $E Z H 2$ elevation, and a positive correlation between the expression of the two genes. EZH2 was reported to positively regulate MYC in glioblastoma cells [37]. Hence, this may set up a feed-forward loop that sustains high levels of Myc and $\mathrm{EZH} 2$, thus deregulating these central regulatory nodes and promoting transformation, and contributing to the oncogenic phenotype.

Reduced miR-26a expression has been noted in various cancers, including hepatocellular carcinoma, thyroid anaplastic carcinoma, rhabdomyosarcoma and

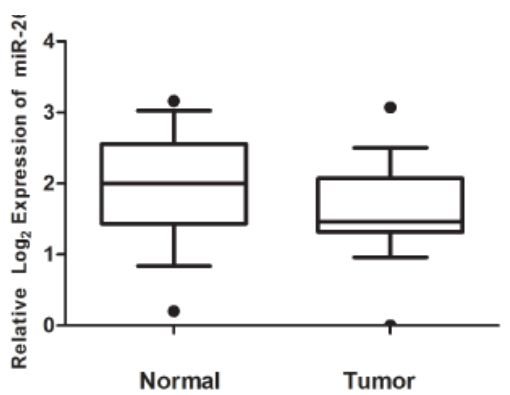

Wilcoxon signed rank test, $\mathrm{p}=0.079$

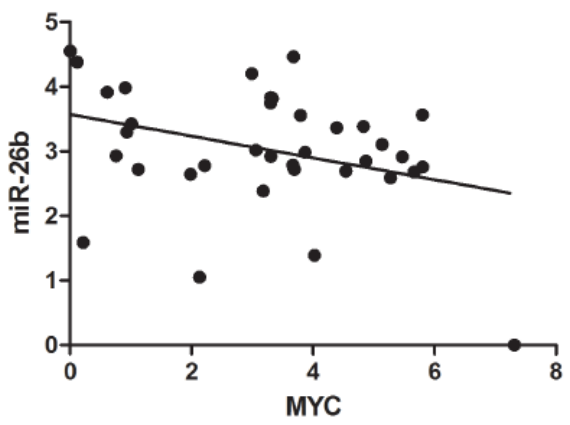

Spearman rank correlation coefficient $=-0.3093$, $\mathrm{p}=0.0664$

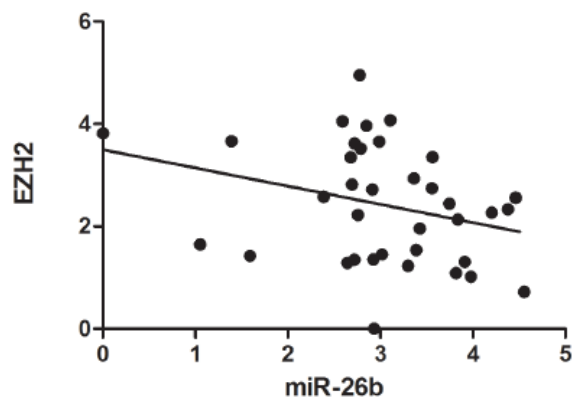

Spearman rank correlation coefficient $=-0.3552$, $\mathrm{p}<0.0392$

Figure 6: MiR-26a Expression in Primary Prostate Cancer Specimens. $(A)$ Reduced miR-26a expression in primary prostate cancer cases, normalized to matched benign prostate tissue. Inverse correlations were observed between $M Y C$ and miR-26a/b $(B)$, as well as miR-26a/b and EZH2 (C). 
clear cell renal cell carcinoma [39-44]. However, miR26a has been reported to be amplified in gliomas, and to promote gliomagenesis [43]. Previous miRNA profiling studies in prostate cancer have reported both the downregulation $[45,46]$, and the up-regulation of miR-26a [4749]. Decreased miR-26b expression has been reported in liver, head and neck cancers, and in hormone refractory prostate cancer $[46,50,51]$, while its upregulation was reported in bladder cancer [52]. Thus, whether miR-26a and miR-26b facilitate oncogenesis, or act as a tumor suppressor, may depend on the cellular context.

By quantitative real-time PCR, we found that the expression of miR-26a was reduced in a high fraction of localized prostate cancer, and correlated negatively with the expression of both $M Y C$ and EZH2. In general, miR$26 \mathrm{~b}$ expression was also reduced in the tumors, though

A

Normal Prostate

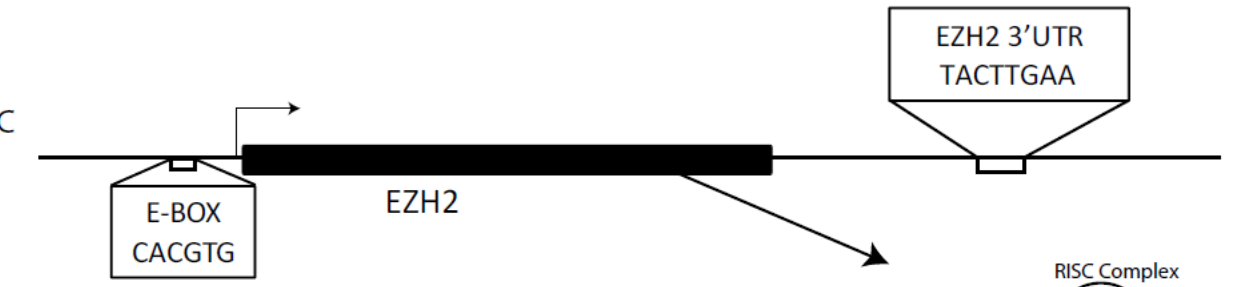

Low Levels of MYC Protein
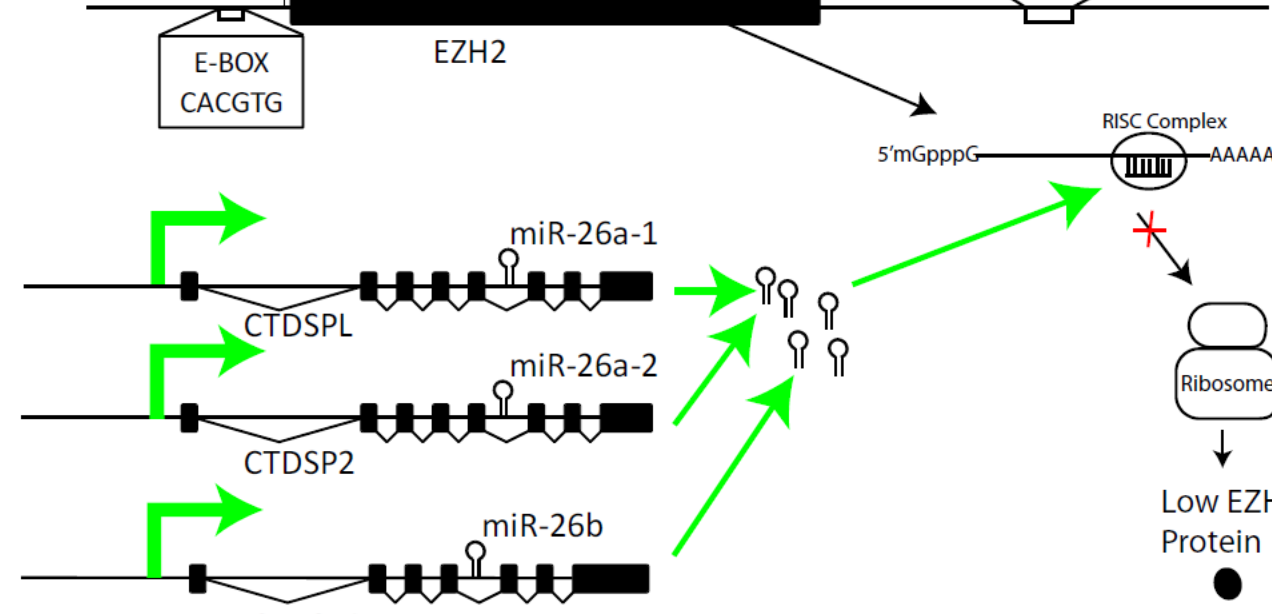

CTDSP1

$\mathrm{B}$

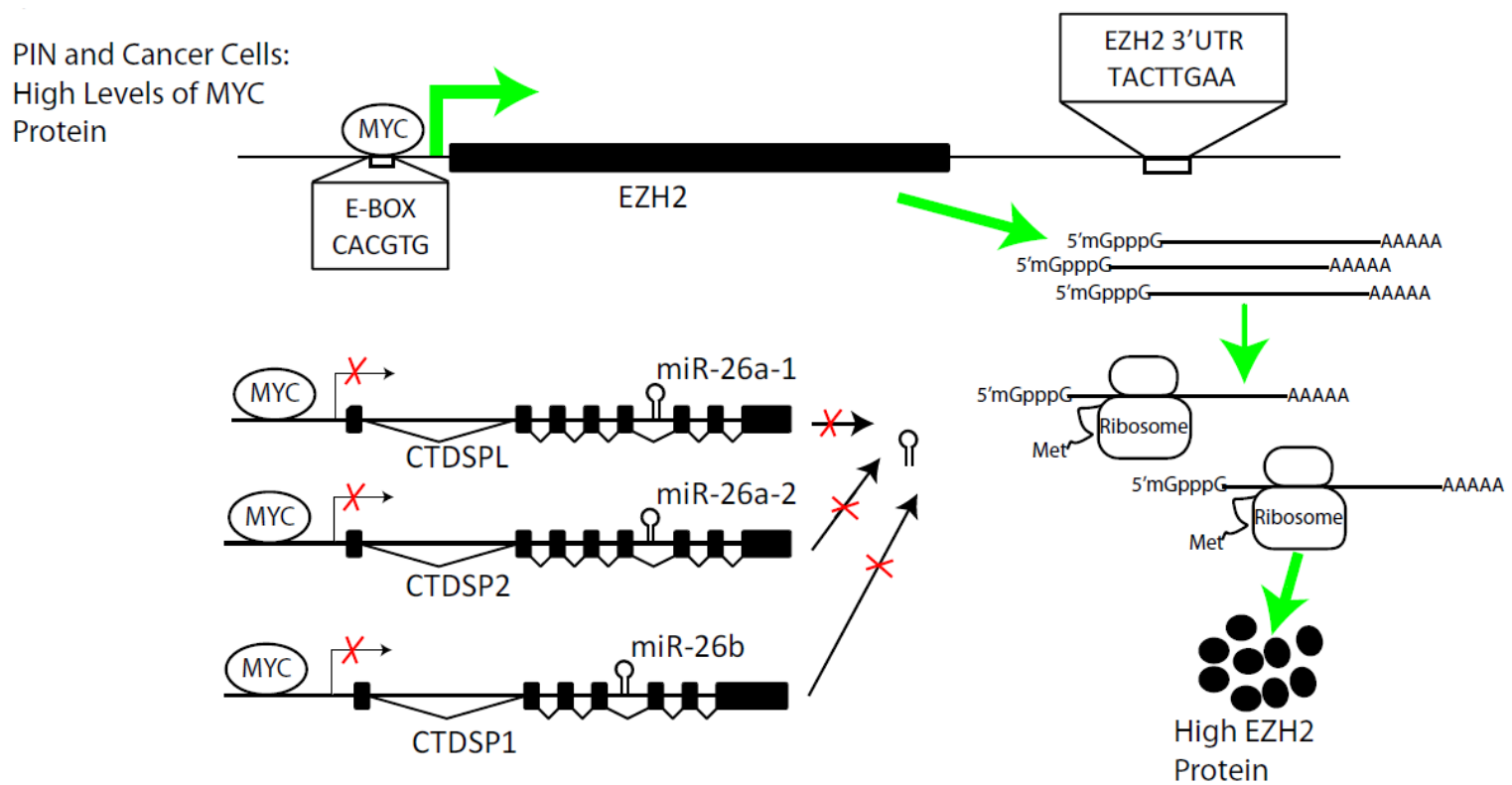

Figure 7: Model of Regulation of EZH2 by Myc by Two Distinct Mechanisms in Prostate Cancer. (A) In normal prostate luminal cells, Myc protein expression is low. Myc-induced EZH2 transcription occurs at a low level, resulting in basal expression levels of EZH2. Since MYC represses the transcription of CTDSPL, CTDSP2 and CTDSP1, when MYC levels are low, these genes, which harbor miR-26a and miR-26b, are actively transcribed. MiR-26a and miR-26b are incorporated into the RISC complex and bind specifically to their complementary site on the 3' UTR of EZH2, destabilizing EZH2 mRNA and repressing its translation. As such, EZH2 is maintained at a low level by transcriptional and post-transcriptional regulatory mechanisms. (B) In prostate cancer, elevated Myc levels drive EZH2 overexpression. MYC binds to the E-box-containing promoter region of EZH2 and activates its transcription. Concurrently, MYC represses CTDSPL, CTDSP2 and CTDSP1, in which miR-26a and miR-26b are embedded. As such, miRNA-mediated post-transcriptional silencing of EZH2 mRNA is reduced. This results in elevated EZH2 protein expression. 
this reduction was not as consistent. Transient transfection of miR-26a and miR-26b mimics into 5 prostate cancer cell lines resulted in suppressed proliferation, indicating that these MYC targets of repression may have tumorsuppressive functions in the context of prostate cancer. In a murine liver cancer model, in which a similar underexpression of miR-26a was observed, targeted delivery of miR-26a showed a therapeutic effect [40]. Thus, similar strategies may be applicable to the treatment of prostate cancer.

In summary, we report that Myc can activate EZH2 expression in prostate cancer by 2 distinct mechanismsvia direct transcriptional activation of the EZH2 promoter, as well as via repression of miR-26a and miR-26b, which themselves can repress EZH2. The frequent and early overexpression of Myc in PIN and primary prostate cancer cases may account in part for the common upregulation of EZH2 in these lesions. A model for how Myc regulates EZH2 is shown in Fig. 7. First, Myc upregulates EZH2 directly by binding to the $E Z H 2$ promoter and stimulating its transcription. Second, by simultaneously binding to and inhibiting transcription of the host genes encoding miR-26a and miR-26b, Myc enforces this upregulation by inhibiting post-transcriptional silencing of EZH2 mRNA. Thus, by binding to 4 separate loci and affecting both activation and repression, Myc coordinates the upregulation of EZH2 protein.

These findings have additional implications for the transformation of prostate epithelial cells. For example, it is quite plausible that Myc may stimulate prostate cancer initiation, in part via EZH2-mediated chromatin remodeling and gene silencing. Hence, these results support the concept that EZH2 may be an early contributor to prostate cancer development [53], in addition to being a potent driver of the progression to aggressive, metastatic disease. EZH2 can modulate the expression of numerous regulatory networks, and there is significant enrichment for EZH2-mediated H3K27me3 polycomb repression signatures in embryonic stem cells, embryonic fibroblasts and advanced prostate cancer [4, 13, 54]. Myc has also been shown to activate an embryonic stem cell-like module of gene expression and can prevent the terminal differentiation of prostate cancer cells (Koh et al., in preparation). Hence, Myc overexpression may drive prostate cancer initiation by perturbing normal prostate differentiation programs and aberrantly activate embryonic stem-cell like programs, in part by the induction of EZH2.

\section{ACKNOWLEDGEMENTS}

This study was supported by the Patrick C. Walsh Prostate Cancer Fund of which AMD is the Peter J. Sharp Scholar, and Prostate SPORE P50CA58236. We wish to thank Helen Fedor, Marcela Southerland, Kristen Lecksell and the Brady Urological Institute Prostate Specimen Repository for fresh prostate tissues and tissue microarrays, and Chi V. Dang, Joshua T. Mendell, William G. Nelson and Alan K. Meeker for critical reading and helpful discussions regarding this manuscript.

\section{REFERENCES}

1. Sparmann A, van Lohuizen M. Polycomb silencers control cell fate, development and cancer. Nature reviews. 2006; 6:846-856.

2. Simon JA, Lange CA. Roles of the EZH2 histone methyltransferase in cancer epigenetics. Mutation research. 2008; 647:21-29.

3. Bracken AP, Dietrich N, Pasini D, Hansen KH, Helin K. Genome-wide mapping of Polycomb target genes unravels their roles in cell fate transitions. Genes \& development. 2006; 20:1123-1136.

4. Lee TI, Jenner RG, Boyer LA, Guenther MG, Levine SS, Kumar RM, Chevalier B, Johnstone SE, Cole MF, Isono K, Koseki H, Fuchikami T, Abe K, Murray HL, Zucker JP, Yuan B et al. Control of developmental regulators by Polycomb in human embryonic stem cells. Cell. 2006; 125:301-313.

5. Varambally S, Cao Q, Mani RS, Shankar S, Wang X, Ateeq B, Laxman B, Cao X, Jing X, Ramnarayanan K, Brenner JC, Yu J, Kim JH, Han B, Tan P, Kumar-Sinha C et al. Genomic loss of microRNA-101 leads to overexpression of histone methyltransferase EZH2 in cancer. Science (New York, NY. 2008; 322:1695-1699.

6. Varambally S, Dhanasekaran SM, Zhou M, Barrette TR, Kumar-Sinha C, Sanda MG, Ghosh D, Pienta KJ, Sewalt RG, Otte AP, Rubin MA, Chinnaiyan AM. The polycomb group protein EZH2 is involved in progression of prostate cancer. Nature. 2002; 419:624-629.

7. Karanikolas BD, Figueiredo ML, Wu L. Comprehensive evaluation of the role of EZH2 in the growth, invasion, and aggression of a panel of prostate cancer cell lines. The Prostate. 2010; 70:675-688.

8. Saramaki OR, Tammela TL, Martikainen PM, Vessella $\mathrm{RL}$, Visakorpi T. The gene for polycomb group protein enhancer of zeste homolog 2 (EZH2) is amplified in latestage prostate cancer. Genes, chromosomes \& cancer. 2006; 45:639-645.

9. Sellers WR, Loda M. The EZH2 polycomb transcriptional repressor--a marker or mover of metastatic prostate cancer? Cancer cell. 2002; 2:349-350.

10. van Leenders GJ, Dukers D, Hessels D, van den Kieboom SW, Hulsbergen CA, Witjes JA, Otte AP, Meijer CJ, Raaphorst FM. Polycomb-group oncogenes EZH2, BMI1, and RING1 are overexpressed in prostate cancer with adverse pathologic and clinical features. European urology. 2007; 52:455-463.

11. Min J, Zaslavsky A, Fedele G, McLaughlin SK, Reczek EE, De Raedt T, Guney I, Strochlic DE, Macconaill LE, Beroukhim R, Bronson RT, Ryeom S, Hahn WC, Loda 
M, Cichowski K. An oncogene-tumor suppressor cascade drives metastatic prostate cancer by coordinately activating Ras and nuclear factor-kappaB. Nature medicine. 2010; 16:286-294.

12. Kunderfranco P, Mello-Grand M, Cangemi R, Pellini S, Mensah A, Albertini V, Malek A, Chiorino G, Catapano $\mathrm{CV}$, Carbone GM. ETS transcription factors control transcription of EZH2 and epigenetic silencing of the tumor suppressor gene Nkx3.1 in prostate cancer. PloS one. 2010; 5:e10547.

13. Yu J, Yu J, Mani RS, Cao Q, Brenner CJ, Cao X, Wang $\mathrm{X}$, Wu L, Li J, Hu M, Gong Y, Cheng H, Laxman B, Vellaichamy A, Shankar S, Li Y et al. An integrated network of androgen receptor, polycomb, and TMPRSS2ERG gene fusions in prostate cancer progression. Cancer cell. 2010; 17:443-454.

14. Meyer N, Penn LZ. Reflecting on 25 years with MYC. Nature reviews. 2008; 8:976-990.

15. Gurel B, Iwata T, Koh CM, Jenkins RB, Lan F, Van Dang C, Hicks JL, Morgan J, Cornish TC, Sutcliffe S, Isaacs WB, Luo J, De Marzo AM. Nuclear MYC protein overexpression is an early alteration in human prostate carcinogenesis. Mod Pathol. 2008; 21:1156-1167.

16. Dang CV, O’Donnell KA, Zeller KI, Nguyen T, Osthus $\mathrm{RC}$, Li F. The c-Myc target gene network. Seminars in cancer biology. 2006; 16:253-264.

17. Chang TC, Yu D, Lee YS, Wentzel EA, Arking DE, West KM, Dang CV, Thomas-Tikhonenko A, Mendell JT. Widespread microRNA repression by Myc contributes to tumorigenesis. Nature genetics. 2008; 40:43-50.

18. Gao P, Tchernyshyov I, Chang TC, Lee YS, Kita K, Ochi T, Zeller KI, De Marzo AM, Van Eyk JE, Mendell JT, Dang CV. c-Myc suppression of miR-23a/b enhances mitochondrial glutaminase expression and glutamine metabolism. Nature. 2009; 458:762-765.

19. O'Donnell KA, Wentzel EA, Zeller KI, Dang CV, Mendell JT. c-Myc-regulated microRNAs modulate E2F1 expression. Nature. 2005; 435:839-843.

20. Zeller KI, Zhao X, Lee CW, Chiu KP, Yao F, Yustein JT, Ooi HS, Orlov YL, Shahab A, Yong HC, Fu Y, Weng Z, Kuznetsov VA, Sung WK, Ruan Y, Dang CV et al. Global mapping of c-Myc binding sites and target gene networks in human B cells. Proceedings of the National Academy of Sciences of the United States of America. 2006; 103:1783417839.

21. Sander S, Bullinger L, Klapproth K, Fiedler K, Kestler HA, Barth TF, Moller P, Stilgenbauer S, Pollack JR, Wirth T. MYC stimulates EZH2 expression by repression of its negative regulator miR-26a. Blood. 2008; 112:4202-4212.

22. Wong CF, Tellam RL. MicroRNA-26a targets the histone methyltransferase Enhancer of Zeste homolog 2 during myogenesis. The Journal of biological chemistry. 2008; 283:9836-9843.

23. Gennarino VA, Sardiello M, Avellino R, Meola N, Maselli
V, Anand S, Cutillo L, Ballabio A, Banfi S. MicroRNA target prediction by expression analysis of host genes. Genome research. 2009; 19:481-490.

24. Iwata T, Schultz D, Hicks J, Hubbard GK, Mutton LN, Lotan TL, Bethel C, Lotz MT, Yegnasubramanian S, Nelson WG, Dang CV, Xu M, Anele U, Koh CM, Bieberich CJ, De Marzo AM. MYC overexpression induces prostatic intraepithelial neoplasia and loss of $\mathrm{Nkx} 3.1$ in mouse luminal epithelial cells. PloS one. 2010; 5:e9427.

25. Watson PA, Ellwood-Yen K, King JC, Wongvipat J, Lebeau MM, Sawyers CL. Context-dependent hormonerefractory progression revealed through characterization of a novel murine prostate cancer cell line. Cancer research. 2005; 65:11565-11571.

26. Zeller KI, Jegga AG, Aronow BJ, O’Donnell KA, Dang $\mathrm{CV}$. An integrated database of genes responsive to the Myc oncogenic transcription factor: identification of direct genomic targets. Genome biology. 2003; 4:R69.

27. Ellwood-Yen K, Graeber TG, Wongvipat J, Iruela-Arispe ML, Zhang J, Matusik R, Thomas GV, Sawyers CL. Mycdriven murine prostate cancer shares molecular features with human prostate tumors. Cancer Cell. 2003; 4:223-238.

28. Koh CM, Gurel B, Sutcliffe S, Aryee MJ, Schultz D, Iwata T, Uemura M, Zeller KI, Anele U, Zheng Q, Hicks JL, Nelson WG, Dang CV, Yegnasubramanian S, De Marzo AM. Alterations in nucleolar structure and gene expression programs in prostatic neoplasia are driven by the MYC oncogene. Am J Pathol. 2011; 178:1824-1834.

29. Salvatori B, Iosue I, Djodji Damas N, Mangiavacchi A, Chiaretti S, Messina M, Padula F, Guarini A, Bozzoni I, Fazi F, Fatica A. Critical Role of c-Myc in Acute Myeloid Leukemia Involving Direct Regulation of miR-26a and Histone Methyltransferase EZH2. Genes Cancer. 2011; 2:585-592.

30. Bachmann IM, Halvorsen OJ, Collett K, Stefansson IM, Straume O, Haukaas SA, Salvesen HB, Otte AP, Akslen LA. EZH2 expression is associated with high proliferation rate and aggressive tumor subgroups in cutaneous melanoma and cancers of the endometrium, prostate, and breast. J Clin Oncol. 2006; 24:268-273.

31. Kleer CG, Cao Q, Varambally S, Shen R, Ota I, Tomlins SA, Ghosh D, Sewalt RG, Otte AP, Hayes DF, Sabel MS, Livant D, Weiss SJ, Rubin MA, Chinnaiyan AM. EZH2 is a marker of aggressive breast cancer and promotes neoplastic transformation of breast epithelial cells. Proceedings of the National Academy of Sciences of the United States of America. 2003; 100:11606-11611.

32. Bracken AP, Pasini D, Capra M, Prosperini E, Colli E, Helin K. EZH2 is downstream of the pRB-E2F pathway, essential for proliferation and amplified in cancer. The EMBO journal. 2003; 22:5323-5335.

33. Tonini T, D’Andrilli G, Fucito A, Gaspa L, Bagella L. Importance of Ezh2 polycomb protein in tumorigenesis process interfering with the pathway of growth suppressive key elements. Journal of cellular physiology. 2008; 
214:295-300.

34. Furusato B, Tan SH, Young D, Dobi A, Sun C, Mohamed AA, Thangapazham R, Chen Y, McMaster G, Sreenath T, Petrovics G, McLeod DG, Srivastava S, Sesterhenn IA. ERG oncoprotein expression in prostate cancer: clonal progression of ERG-positive tumor cells and potential for ERG-based stratification. Prostate cancer and prostatic diseases. 2010; 13:228-237.

35. Tang X, Milyavsky M, Shats I, Erez N, Goldfinger N, Rotter V. Activated p53 suppresses the histone methyltransferase EZH2 gene. Oncogene. 2004; 23:5759-5769.

36. Muller H, Bracken AP, Vernell R, Moroni MC, Christians F, Grassilli E, Prosperini E, Vigo E, Oliner JD, Helin $\mathrm{K}$. E2Fs regulate the expression of genes involved in differentiation, development, proliferation, and apoptosis. Genes \& development. 2001; 15:267-285.

37. Suva ML, Riggi N, Janiszewska M, Radovanovic I, Provero P, Stehle JC, Baumer K, Le Bitoux MA, Marino D, Cironi L, Marquez VE, Clement V, Stamenkovic I. EZH2 is essential for glioblastoma cancer stem cell maintenance. Cancer research. 2009; 69:9211-9218.

38. Cao P, Deng Z, Wan M, Huang W, Cramer SD, Xu J, Lei M, Sui G. MicroRNA-101 negatively regulates Ezh2 and its expression is modulated by androgen receptor and HIF1alpha/HIF-1beta. Mol Cancer. 2010; 9:108.

39. Ciarapica R, Russo G, Verginelli F, Raimondi L, Donfrancesco A, Rota R, Giordano A. Deregulated expression of miR-26a and Ezh2 in rhabdomyosarcoma. Cell Cycle. 2009; 8:172-175.

40. Kota J, Chivukula RR, O'Donnell KA, Wentzel EA, Montgomery CL, Hwang HW, Chang TC, Vivekanandan P, Torbenson M, Clark KR, Mendell JR, Mendell JT. Therapeutic microRNA delivery suppresses tumorigenesis in a murine liver cancer model. Cell. 2009; 137:1005-1017.

41. Maillot G, Lacroix-Triki M, Pierredon S, Gratadou L, Schmidt S, Benes V, Roche H, Dalenc F, Auboeuf D, Millevoi S, Vagner S. Widespread estrogen-dependent repression of micrornas involved in breast tumor cell growth. Cancer research. 2009; 69:8332-8340.

42. Visone R, Pallante P, Vecchione A, Cirombella R, Ferracin M, Ferraro A, Volinia S, Coluzzi S, Leone V, Borbone E, Liu CG, Petrocca F, Troncone G, Calin GA, Scarpa A, Colato $\mathrm{C}$ et al. Specific microRNAs are downregulated in human thyroid anaplastic carcinomas. Oncogene. 2007; 26:7590-7595.

43. Huse JT, Brennan C, Hambardzumyan D, Wee B, Pena J, Rouhanifard SH, Sohn-Lee C, le Sage C, Agami R, Tuschl T, Holland EC. The PTEN-regulating microRNA miR-26a is amplified in high-grade glioma and facilitates gliomagenesis in vivo. Genes Dev. 2009; 23:1327-1337.

44. Heinzelmann J, Henning B, Sanjmyatav J, Posorski N, Steiner T, Wunderlich H, Gajda MR, Junker K. Specific miRNA signatures are associated with metastasis and poor prognosis in clear cell renal cell carcinoma. World journal of urology. 2011; 29:367-373.

45. Ozen M, Creighton CJ, Ozdemir M, Ittmann M. Widespread deregulation of microRNA expression in human prostate cancer. Oncogene. 2008; 27:1788-1793.

46. Porkka KP, Pfeiffer MJ, Waltering KK, Vessella RL, Tammela TL, Visakorpi T. MicroRNA expression profiling in prostate cancer. Cancer research. 2007; 67:6130-6135.

47. Ambs S, Prueitt RL, Yi M, Hudson RS, Howe TM, Petrocca F, Wallace TA, Liu CG, Volinia S, Calin GA, Yfantis HG, Stephens RM, Croce CM. Genomic profiling of microRNA and messenger RNA reveals deregulated microRNA expression in prostate cancer. Cancer research. 2008; 68:6162-6170.

48. Volinia S, Calin GA, Liu CG, Ambs S, Cimmino A, Petrocca F, Visone R, Iorio M, Roldo C, Ferracin M, Prueitt RL, Yanaihara N, Lanza G, Scarpa A, Vecchione A, Negrini $\mathrm{M}$ et al. A microRNA expression signature of human solid tumors defines cancer gene targets. Proceedings of the National Academy of Sciences of the United States of America. 2006; 103:2257-2261.

49. Mahn R, Heukamp LC, Rogenhofer S, von Ruecker A, Muller SC, Ellinger J. Circulating microRNAs (miRNA) in serum of patients with prostate cancer. Urology. 2011; 77:1265 e1269-1216.

50. Ji J, Shi J, Budhu A, Yu Z, Forgues M, Roessler S, Ambs S, Chen Y, Meltzer PS, Croce CM, Qin LX, Man K, Lo CM, Lee J, Ng IO, Fan J et al. MicroRNA expression, survival, and response to interferon in liver cancer. The New England journal of medicine. 2009; 361:1437-1447.

51. Liu X, Chen Z, Yu J, Xia J, Zhou X. MicroRNA Profiling and Head and Neck Cancer. Comparative and functional genomics. 2009:837514.

52. Gottardo F, Liu CG, Ferracin M, Calin GA, Fassan M, Bassi P, Sevignani C, Byrne D, Negrini M, Pagano F, Gomella LG, Croce CM, Baffa R. Micro-RNA profiling in kidney and bladder cancers. Urologic oncology. 2007; 25:387-392.

53. Karanikolas BD, Figueiredo ML, Wu L. Polycomb group protein enhancer of zeste 2 is an oncogene that promotes the neoplastic transformation of a benign prostatic epithelial cell line. Mol Cancer Res. 2009; 7:1456-1465.

54. Yu J, Yu J, Rhodes DR, Tomlins SA, Cao X, Chen G, Mehra R, Wang X, Ghosh D, Shah RB, Varambally S, Pienta KJ, Chinnaiyan AM. A polycomb repression signature in metastatic prostate cancer predicts cancer outcome. Cancer research. 2007; 67:10657-10663. 